\title{
LOS MÉDICOS IRLANDESES Y LAS IDEAS (PRE)ILUSTRADAS: RAYMOND EVERARD (1675-1754)
}

\author{
Ekain Cagigal \\ Investigador independiente \\ Email: ekaincagigal@yahoo.com \\ ORCID iD: https://orcid.org/0000-0002-4300-199X
}

Recibido: 29 octubre 2019; Aceptado: 14 mayo 2020

Cómo citar este artículo/Citation: Cagigal, Ekain (2020) “Los Médicos irlandeses y las ideas (pre)ilustradas: Raymond Everard (16751754)" Asclepio, 72(2): p315. https://doi.org/10.3989/asclepio.2020.16

RESUMEN: La historiografía ha mostrado extensamente cómo los médicos irlandeses tuvieron un papel de primer nivel en la medicina del siglo XVIII a lo largo de toda la Monarquía Hispánica. Sin embargo, más allá de las prominentes figuras ligadas a los círculos cortesanos y militares -tales como, Higgins, Purcell, Gorman u O'Scanlan-, puede reivindicarse todo un número de doctores irlandeses que desempeñaron su ejercicio en ámbitos público-privados de menor proyección, pero con sólidos posicionamientos profesionales, y en muchos de los casos, vehiculizando las nuevas corrientes ideológicas del continente, adquiridas en la trayectoria de su emigración. Así, Raymond Everard, natural del condado de Waterford (Irlanda), representa muy fielmente el arquetipo de médico irlandés que, tras un paso por las universidades y los círculos pre-ilustrados franceses, recaló en Bilbao como médico municipal, atendiendo a la villa durante casi cuarenta años, e impregnándola de la modernidad técnico-científica del momento a través de su labor médica.

PALABRAS CLAVE: Medicina; Irlanda; Edad Moderna; París; Bilbao.

\section{IRISH DOCTORS AND (PRE)ENLIGHTENED IDEAS: RAYMOND EVERARD (1675-1754)}

ABSTRACT: Historiography has extensively demonstrated that Irish doctors played a very relevant role in the medicine of the Spanish Monarchy along $18^{\text {th }}$ century. Nevertheless, beyond the prominent figures linked to the court and military circles -such as Higgins, Purcell, Gorman or O'Scanlan-, a significant number of Irish doctors can be claimed, who practised medicine in public-private spheres of less projection. In any case, they were well established professionals, who conveyed the new ideological currents generated in the continent and acquired along their migration pathways. Raymond Everard, born in co. Waterford (Ireland), truly depicts the archetype of the Irish doctor who, after being immersed in the French enlightened circles and universities, settled down in Bilbao as municipal doctor, where he took care of the town for nearly forty years, imbuing it with the existing technical-scientific modernity through his medical work.

KEY WORDS: Medicine; Ireland; Early Modern Period; Paris; Bilbao. 


\section{INTRODUCCIÓN}

Durante la Edad Moderna la diáspora irlandesa hacia el continente europeo manifestó múltiples corrientes y facetas políticas, socio-demográficas, culturales, profesionales y, por añadido, las particulares vicisitudes que sufrió cada emigrante a lo largo de su singular exilio. Durante las últimas dos décadas han sido numerosos y variados los estudios historiográficos llevados a cabo desde diferentes perspectivas, ámbitos geográficos y colectivos socio-profesionales -nobleza, militares, clero, comerciantes, etc (O'Connor, 2001; O'Connor, 2006; Worthington, 2010; Villar García, 2000; Eiras Roel, 2004; Lario de Oñate, 2001; Recio Morales et al., 2002).

La llegada a España de los exiliados católicos irlandeses comenzó ya desde el siglo XVII, asociada a la invasión inglesa de Irlanda y la instauración de las leyes represivas y discriminatorias decretadas por Oliver Cromwell contra la población católica. $Y$ tuvo lugar, aún en mayor medida, en dos momentos históricos posteriores. El primero se dio a finales del siglo XVII y el segundo, a comienzos del XVIII -que aún tuvo continuidad durante toda la primera mitad de la centuria. La primera fase se produjo a resultas del tratado de Limerick donde se rubricaba la derrota de las tropas católicas irlandesas, y la mayor parte de las tropas y la población irlandesas se dirigieron hacia Francia y, en menor medida, aunque también notablemente, hacia España. La segunda fase del movimiento migratorio tuvo lugar a comienzos de este último siglo, cuando, tras la Guerra de Sucesión española, se instauró en España la monarquía borbónica y gran parte del contingente irlandés -principalmente militar- establecido en Francia se trasladó a tierras españolas.

Una pequeña parte de los grupos militares irlandeses lo integraban los médicos y cirujanos que, formados mayoritariamente en las universidades francesas, atendían las demandas asistenciales de los activos regimientos irlandeses al servicio de las coronas francesa y española. Muchos de ellos progresaron rápidamente en sus carreras alcanzando puestos de alta relevancia en los estamentos españoles, alineado en parte con los puestos de poder que ciertas figuras irlandesas representaron en la monarquía borbónica.

Así pues, la carrera de estos profesionales de la medicina de origen irlandés merece un estudio detallado y particular, el cual ha sido ya abordado por ciertos autores en cuanto a las pautas genéricas de este grupo (White, 2008) y, más concretamente, para alguna figura individual de particular interés (Amenedo Costa, 2010; Beltrán, 1939). La preeminencia de los doctores irlandeses durante la Edad Moderna se relaciona con varios ámbitos de relevancia. Por un lado, se apunta como objeto de análisis su papel en las comunidades irlandesas en el exilio continental. En segundo lugar, el estudio de la evolución de sus carreras profesionales se presenta como un enfoque singular, pero muy representativo a la vez, del colectivo de emigrados irlandeses: educación y formación, y puestos y cargos desempeñados en las sociedades de acogida. Además, asociado a esta formación, los médicos irlandeses jugaron un papel fundamental desde el punto de vista de los avances científicomédicos, particularmente en un período caracterizado por las ideas e inquietudes de la llustración o, en general, del caldo de cultivo ideológico pre-ilustrado.

Los practicantes de la medicina irlandeses podrían categorizarse en dos grandes grupos en cuanto a las posiciones profesionales que ocuparon en la monarquía hispánica: cargos institucionales de alto estrato -bien en la corte, en el ejército o en las corporaciones médicas de la Corona- y cargos público-privados de menor proyección. Entre los primeros, asociado a esa proyección institucional y notoriedad histórica, se han llevado a cabo diversos estudios, tal como son el caso de Timoteo O'Scanlan, Juan Higgins, o Miguel O'Gorman. Para los segundos, aunque más numerosos de lo imaginado a priori, la atención ha sido menor, puesto que en muchos casos las fuentes y las referencias documentales son escasas y dificultan el seguimiento de estas figuras (Walsh, 1989; Tena, 2008, p. 90; Chaparro, 1983, p. 534). A pesar de que este último grupo podría presentar un interés histórico de menor entidad, sí que proporciona un modelo de profesional emigrado con mecanismos de inserción, interacción y evolución en las sociedades receptoras bien diferenciados y definidos; y denota que, en muchos casos, la proyección social y el impacto de su trabajo se produjo también de forma notoria, pero de un modo más geográficamente localizado, esto es, ligado al desarrollo de una región o de una ciudad. Es este segundo perfil el que pretende reflejar la presente publicación a través de la figura de Raymond Everard, quien, a pesar de no haber transcendido al nivel de otros médicos irlandeses en tierras hispanas, sí que se asentó en la villa de Bilbao con una proyección socio-profesional consolidada y duradera. 
Raymond Everard llegó a Bilbao a comienzos del siglo XVIII, en un momento en el que el puerto de la villa comenzaba su época dorada, fruto de un comercio pujante asentado en las relaciones comerciales de la red portuaria del Atlántico. Los comerciantes vizcaínos fomentaban una vocación aperturista y los extranjeros vislumbraron la villa vizcaína como un nodo comercial estratégico. Así, la exportación de la lana castellana y el hierro vizcaíno, y la importación de otros productos como bacalao, lienzos, cueros, y otros artículos consiguieron colocar a Bilbao en las triangulaciones de transacciones comerciales que se daban habitualmente entre el norte de Europa, las islas británicas, los puertos norteamericanos muchas veces, y los puertos peninsulares (Guiard, 1972; Zabala, 1994; Basurto Larrañaga, 1983). En definitiva, esta apertura al comercio exterior redundó en una mayor interacción con las grandes potencias europeas, no solo a nivel mercantil, financiero y económico, sino también a nivel social, cultural, ideológico, científico e, incluso, artístico. La nobleza -activa en el comercio-y, quizá en menor medida, la burguesía mercantil bilbaínas manifestaron una atracción por los avances técnico-científicos, el aprendizaje y el conocimiento de las nuevas ideas y movimientos culturales europeos. Un buen indicador de ello, son las numerosas y bien nutridas bibliotecas que ostentaban estas clases privilegiadas en sus casas. Era este un Bilbao que ya se preparaba para las corrientes ilustradas -que se consolidarían años después-, que recibía con agrado los nuevos hilos de pensamiento, y que gestaba en cierto modo los perfiles de hombres ilustrados que surgirían algún tiempo después -formados en universidades europeas y que viajaban visitando las grandes ciudades del continente (Astigarraga, 2003, pp. 23-35) ${ }^{1}$. En particular, se ajustaba a un gusto por lo afrancesado, de donde se asumía que procedían las pautas de la modernidad en ese momento.

Esta inquietud intelectual era emergente en la villa vizcaína y así, concretamente en el caso de la medicina, las propias instituciones bilbaínas buscaron atraer a la ciudad a talentos que ejercieran su trabajo al amparo de las doctrinas médicas más innovadoras. En este escenario se enmarca la figura de Everard, cuya formación y -presumiblemente- capacidades respondían a las inquietudes despertadas y demandadas entre las instituciones de Bilbao y que, de algún modo, se ajustaba al perfil de hombre pre-ilustrado formado y educado en las universidades francesas más innovadoras y reformistas.
De este modo, su trayectoria profesional y personal dibuja un recorrido histórico que aglutina muchos de los grandes escenarios asociados al dinámico siglo XVIII. Por un lado, su huida de Irlanda refleja las cruentas guerras de religión que marcaron el devenir de la Edad Moderna europea. Su formación francesa manifiesta el despertar a un nuevo modo de entender el mundo, tanto a nivel ideológico -tal como acabaría eclosionando a final de siglo- como a nivel científico -con el cambio de paradigma médico impulsado desde las universidades europeas. Por añadido, su estancia en Saint Malo representaba las vivencias de una comunidad exiliada -la irlandesa- que subsistía y progresaba en tierras extrañas, viviendo de primera mano los avatares marítimos del siglo-actividad mercantil, corso, contrabando, piratería, etc. Al igual que en Saint Malo, se estableció más tarde en una ciudad como Bilbao donde pudo vivir de primera mano el florecimiento de una villa basado en las redes comerciales europeas, e incluso americanas, de su puerto. $Y$ por añadido, sus múltiples episodios de vida en diferentes localizaciones y su clase social le permitieron interactuar con personalidades de alta relevancia o posición -de la nobleza, el clero, o la burguesía- y muy posiblemente con influyentes mentalidades (pre) ilustradas de las ciencias, la cultura, o el pensamiento; que a buen seguro enriquecieron su personalidad.

\section{WATERFORD: ORIGEN Y FAMILIA}

No hay referencias directas al nacimiento de Raymond Everard; sin embargo, existen otras fuentes que permiten estimar la fecha del mismo, aunque con ligeras discrepancias. A partir de ciertos testimonios surgen dos posibles años de nacimiento, 1675 o 1676 siendo mayoritaria la primera fecha ${ }^{2}$. Así pues, su nacimiento se sitúa en plena ocupación inglesa tras la conquista de Cromwell años atrás y en los albores de las Williamite Wars. Raymond nació en el condado de Waterford, aunque no está claro en qué localidad.

Los padres de Raymond fueron Philip Everard y Margaret O'Kane; sus abuelos paternos, William Everard y Julianne O'Coultan; y sus abuelos maternos, John O'Kane y Margaret O'Carroll. Todos ellos procedían del mismo condado de Waterford ${ }^{3}$. En cuanto a las casas solares de sus apellidos, parece claro que la ascendencia de Raymond Everard era de familias nobles bien posicionadas en el entorno geográfico de 
la frontera entre el condado de Tipperary y el condado de Waterford.

No se dispone de ninguna referencia a sus primeros años de vida en Irlanda. Sin embargo, se sabe por propia declaración de Raymond que abandonó la isla con aproximadamente 18 años: (...) en el tiempo que estuvo en Vaterfordia de dho reino de Yrlanda de donde es natural que abra que salio veinte y siete años poco mas o menos [declaración de 1720] (.... 4 . Esta fecha se corresponde con la finalización de la Guerra de los Dos Reyes, la cual se decantó a favor de Guillermo de Orange y provocó la vuelta al reinado protestante en Inglaterra. Como consecuencia, miles de católicos irlandeses buscaron refugio en las tierras de su aliado francés, y así pareció hacerlo también el joven Everard, quizá en compañía de algún pariente o compañero que militó en el ejército jacobita ${ }^{5}$. Sin embargo, más allá de la motivación socio-política para la migración francesa, Everard se encontraba en estas fechas en plena edad de comenzar estudios superiores. Así, perteneciendo a lo que parecía ser una familia católica bien posicionada económicamente, la educación que requería debía llevarse a cabo fuera de Irlanda. Se desconoce si buscaba ya una formación médica antes de dejar Irlanda o fue más tarde cuando cultivó esta vocación. En cualquier caso, la educación parisina era una de las mejores ofertas europeas tanto para los estudios de teología -propios de muchos exiliados irlandeses- como para los de derecho, medicina u otras carreras. De este modo, la fecha de salida de Raymond hacia París concuerda con la enseñanza médica, que requería en esa época entre cuatro y cinco años, a los cuales había que añadir ciertos cursos previos - por lo general, una titulación de bachiller en artes- que se exigían, en ocasiones, como requisito de acceso a los estudios superiores (Ridder-Symoens, 2010, pp. 47-8). Asumiendo, como se verá más adelante, que Everard se graduó como médico con el nacimiento del nuevo siglo, el comienzo de su instrucción francesa se correlaciona con el abandono de su patria.

\section{PARÍS: EDUCACIÓN Y JACOBITISMO}

Tras el Tratado de Limerick, la corte de Saint-Germain-en-Laye acogió el exilio del rey Jacobo II, y de forma genérica, toda Francia albergó el destierro de miles de católicos irlandeses. En este contexto histórico, París representaba un destino con múltiples atractivos para los exiliados irlandeses. Por un lado, era la capital de la nación católica que, durante finales del siglo XVII, dio asilo en mayor medida a miles de expatriados irlandeses. La corte del rey Jacobo se encontraba en Saint-Germain-en-Laye, a las afueras de París, lo que permitía mantenerse cerca de los círculos de poder en el exilio. Pero, además, la llustración parisina ofrecía numerosas oportunidades en los múltiples ámbitos de la ciencia y de las artes. Así, este centro neurálgico del conocimiento dieciochesco se convertía en destino de todos aquellos que ansiaban una educación de calidad. Fue este escenario el que llevó a muchos irlandeses a continuar o iniciar su formación en varias carreras profesionales en $\mathrm{Pa}$ rís. Particularmente, en el ámbito de la medicina la capital francesa monopolizaba, junto con Montpellier, los centros de excelencia para la formación de los futuros profesionales médicos (Gelfand, 2010), y como consecuencia, sirvió de centro educativo para muchos de los médicos irlandeses que ejercerían por toda Europa durante el siglo XVIII. Entre 1640 y 1800, alrededor de 1300 irlandeses se graduaron en facultades de medicina fuera de su país, de los cuales más de la mitad lo hizo en universidades francesas (Brockliss, 2010, pp. 76-9).

Bajo tal perspectiva, los estudiantes católicos irlandeses manifestaron un patrón que respondía, en mayor o menor medida, a un perfil uniforme y homogéneo de formación médica e integración social. En su mayor parte procedían de familias con la suficiente posición económica como para sufragar los gastos de su formación académica -lo cual suponía varios años de estudios- y la manutención en la capital parisina -una de las ciudades más caras de la época. Sin embargo, la educación en medicina era en muchos casos una vía de progreso social y económico que posicionara al futuro médico de forma privilegiada, comúnmente integrándose en los regimientos irlandeses que servían en Francia (Brockliss, 2010, p. 106). En cualquier caso, la formación y la obtención del título de doctor eran aspectos muy distintos en términos económicos. La graduación en prestigiosas facultades de medicina requería la superación de una exigente serie de pruebas y exámenes, que más allá de la dificultad técnica, representaban un elevado coste monetario. Graduarse en París suponía estudiar durante, al menos, seis años y un coste entre 5000 y 7000 livres. Y es en este punto donde se manifestaba claramente la escasez de recursos financieros de los estudiantes irlandeses. De los aproximadamente 700 médicos irlandeses graduados en Francia entre los siglos XVII y XVIII, alrededor de 600 lo hicieron en la universidad de 
Reims. Esta facultad no constituía en ningún sentido un centro de particular relevancia educativa y, lo que es más, no hay evidencias de que ninguno de los 600 irlandeses graduados allí estudiaran en tal centro académico. La exclusiva justificación de esta práctica era la facilidad -a menudo se realizaba en un examen de un único día- y el coste del título que ofertaba la Facultad de Champagne -alrededor de 300 livres. No obstante, la formación médica de los estudiantes irlandeses previa a su examen en Reims se llevaba a cabo París. Los datos disponibles apuntan a que los médicos en formación dedicaban entre 3 y 4 años a la amplia oferta médica que ofrecía la capital francesa (Brockliss, 2009, p. 83-95). Durante el siglo XVIII, se impartían lecciones de medicina principalmente en cuatro lugares de París: las Escuelas de Medicina y Cirugía, el Collège Royal y el Jardin du Roi. Sin embargo, los estudiantes solían complementar la asistencia a estos centros con lecciones privadas, visitando los hospitales o acudiendo a sesiones de la Academia de Ciencias (Gelfand, 2010, pp. 225-7).

En cualquier caso, los títulos obtenidos en Reims a reducidos costes tenían su contrapartida, puesto que no proporcionaban la posibilidad de ejercer en París o en la propia ciudad de Reims, lo cual obligaba a los recién graduados a buscar su futuro lejos de sus centros formativos, y muy a menudo fuera del territorio francés (Brockliss, 2009, pp. 81-104). De hecho, esta laxitud en la obtención del grado médico en Reims tuvo su repercusión en un muy limitado número de profesionales que alcanzaron carreras ilustres en Francia.

En cuanto a la integración social de los estudiantes de medicina procedentes de Irlanda durante los siglos XVII y XVIII puede apuntarse que se realizó con cierta facilidad, dado que en el centro de París se había consolidado una importante comunidad irlandesa a lo largo de los años precedentes. Principalmente el núcleo de este grupo se asentaba en el Irish College de la capital, fundado años atrás, y en el grupo de clérigos que recibían su formación y ordenación en Francia con objeto de volver a Irlanda como sacerdotes católicos. Sin embargo, el carácter religioso de los centros educativos irlandeses en París se fue diversificando y a principios del siglo XVIII el Irish College también sirvió de residencia a estudiantes no ordenados, de los cuales no todos seguían la vía religiosa. Además del propio Irish College, se tiene constancia de que hubo estudiantes irlandeses que residieron durante finales del siglo XVII y principios del XVIII en el Collège des Grassins y en la rue Traversine (Chambers, 2006, pp. 103-129). Estas tres ubicaciones se encontraban en un entorno muy próximo entre sí, y casualmente muy cercanas a los centros de enseñanza médicos citados anteriormente. La red educativa de irlandeses en París se encontraba soportada en cierta medida por las boursiers destinadas principalmente a la formación de clérigos, aunque podría haber ocurrido que puntualmente dieran apoyo a otro tipo de instrucción o bien a sacerdotes que, habiendo comenzado sus estudios hacia la misión clerical, redirigieran con el paso del tiempo sus metas profesionales (Chambers, 2008).

A pesar de que no se dispone de demasiadas referencias relativas a la estancia de Raymond Everard en París, hay ciertas pruebas documentales que confirman un perfil de estudiante de medicina muy similar al presentado por la bibliografía. Al igual que sus muchos compatriotas médicos, obtuvo su título de medicina en la facultad de Reims ${ }^{6}$, otorgado por el médico Rodolphe Le Large (Paris, 1838, p. 381). Se desconoce la fecha exacta de su graduación dado que no figura en el registro de graduados de Reims ${ }^{7}$; sin embargo, la edad promedio de titulación de otros médicos irlandeses formados en Francia se situaba en torno a los 26 años $^{8}$, lo que apuntaría al año 1702. Casualmente, esta fecha se corresponde con el año de su matrimonio, lo cual podría confirmar esta estimación considerando que con su título de médico disponía de un medio para el sustento de los suyos y poder ganarse así el favor de la familia de su mujer para desposarse con ella. Por añadido, ese mismo año residía en la demarcación de la parroquia de Saint Étienne-du-Mont, la cual se ubica en el mismo entorno urbano de París donde se concentraba la comunidad de irlandeses detallada previamente y los principales centros de formación médica de la capital francesa.

A partir de todo ello se puede proponer el siguiente perfil. Raymond Everard procedía de una familia bien posicionada en su Waterford natal -ciertos parientes suyos pertenecían a la nobleza9 ${ }^{9}$, aunque no propiamente con títulos nobiliarios, sino perteneciente a la clase media. La posición de la familia proporcionó a Raymond los medios para estudiar medicina en París, a donde se dirigió probablemente siguiendo el exilio jacobita posterior al Tratado de Limerick. Es probable que, ya en Irlanda, recibiera parte de su educación básica -incluyendo las materias propias de la propedéutica de la época-, necesaria para acceder a los 
estudios de medicina (Ridder-Symoens, pp. 47-89). La intención de su instrucción médica sería la de dotarle de unas oportunidades de futuro y una vía de progreso social que recuperara o mantuviera al menos la posición social de una rama de la familia Everard, tal vez, en cierto declive. Aprovechando esta oportunidad se formó en París durante la década de 1690, y obtuvo su titulación en Reims poco después de 1700. Entre los años 1691 y 1710, 39 estudiantes de medicina se graduaron en Reims. Es muy probable que compartiera con muchos de ellos sus vivencias académicas y vitales en París. Residió en el entorno de Saint-Étienne-du-Mont, lo que induce a suponer que conviviría con otros irlandeses vinculados a tal distrito parisino: el Collège de Irlandais (o por aquel entonces Collège des Lombards), el Collège de Grássins o en la rue Traversine. No hay constancia documental de su formación en París ni en los centros apuntados anteriormente, pero todos ellos se ubicaban cercanos a su residencia, lo que ratifica muy probablemente su instrucción parisina.

Aunque es probable que viviera mayoritariamente en el centro urbano de París, mantenía vínculos con la corte jacobita. Y, en efecto, su matrimonio se ofició en la parroquia de Saint-Germain-en-Laye, además de que ciertos testimonios apuntan a su presencia en los círculos cortesanos: "asi en la ciudad de París como en la corte de San German, hallandose el testigo estudiando (...) Diego Linch Arzobispo que fue de Tuam a $q^{n}$ conozio en dichas ciudades de París y Corte de San German"10. Es previsible que la relación con el arzobispo Lynch fuera exclusivamente circunstancial, dada la relevancia que tenía la figura del arzobispo de Tuam y dado que este hacía visitas esporádicas a la corte jacobita, estableciendo únicamente su residencia en Francia durante los últimos años de su vida (O'Connor, 2004); no obstante, el solo hecho de moverse en ámbitos en los que coincidiera con él apunta a que Everard estaba en contacto con ciertos colectivos de elevado estrato entre la comunidad irlandesa del continente.

En 1702, probablemente tras finalizar sus estudios, Raymond Everard contrajo matrimonio con Mary Grace Butler en la parroquia de Saint Germain-en-Laye ${ }^{11}$. Es de suponer que ambos se conocieran en la corte del rey Jacobo, puesto que ella residía en Saint Germain-en-Laye. Mary Grace Butler fue hija de James Butler y Grace Norton, nativos del condado de Waterford, al igual que la familia de Everard ${ }^{12}$. Las amonestaciones para el matrimonio de Everard y Butler se hicieron públicas el 27 julio de 1702, y los esponsales se celebraron el 9 de septiembre de ese mismo año.

Con un título de médico que no le permitía trabajar en París, era necesario buscar un destino en el que ejercer la medicina para ganarse la vida. Así, tres años después de su matrimonio Everard se encontraría en Saint Malo, enclave bretón con una importante colonia de irlandeses.

\section{SAINT MALO: FAMILIA Y EXILIO IRLANDÉS}

Desde finales del siglo XVI las costas bretonas fueron foco de cierta presencia irlandesa, principalmente ligado a las relaciones comerciales establecidas entre ambas regiones. Durante el siglo XVII el asentamiento irlandés en Bretaña fue en aumento y en 1660 ya se contabilizan, de forma conservadora, alrededor de 1000 irlandeses en dichas tierras ${ }^{13}$. A finales de siglo y comienzos del XVIII, como consecuencia de la diáspora jacobita, la migración fue aún más considerable llegando a formarse numerosas comunidades irlandesas a lo largo de toda la costa francesa, en enclaves tales como Morlaix, Quimper, Quimperlé, Nantes, La Rochelle, etc (Ó Ciosáin, 2001; Le Noac'h, 2006; Clarke de Dromantin, 2005). Las razones para la elección de las costas bretonas como destino tuvieron, en origen, una motivación puramente comercial al abrigo del floreciente comercio de sus puertos. Sin embargo, a medida que trascurría el siglo XVII y las guerras de religión europeas marcaban las pautas socio-demográficas, el interés de Bretaña se complementó con otro tipo de propósitos, tales como el acuartelamiento de tropas militares para un eventual ataque del ejército francés -incorporando los regimientos irlandeses- con el propósito de recuperar Irlanda o de atacar Inglaterra, como la cercanía marítima que facilitaba el numeroso tránsito de navíos en los cuales se permitía a los clérigos irlandeses formados en Francia regresar a su tierra a difundir la fe católica en la llamada Misión de Irlanda, como el establecimiento de una flota de navíos corsarios que asediaran el comercio inglés en el Canal de La Mancha, etc. (Téllez Alarcia, 2002; Ó Ciosáin, 2006).

Entre las ciudades bretonas que acogieron comunidades de emigrantes irlandeses destaca particularmente Saint Malo, donde desde principios del siglo XVI habían existido intercambios comerciales con ciudades irlandesas. A comienzos del siglo XVIII la 
comunidad malouine de irlandeses estaba fuertemente consolidada y cohesionada. Aunque el origen de los irlandeses de Saint Malo fue diverso, cabe destacar ciertas ciudades de procedencia, como Cork, GaIway, Limerick y Waterford. Mayoritariamente la actividad de esta comunidad estaba asociada, como se ha indicado, a las redes comerciales, incluyendo mercaderes, capitanes de barco, armadores y marineros; sin embargo, con el exilio jacobita y el aumento de la emigración, aparecieron otros muchos perfiles: militares, clérigos, doctores y cirujanos, sastres, profesores, etc. (Lyons, 2000).

Alrededor de 1703, tras su graduación y matrimonio, Raymond Everard se trasladó a Saint Malo. Son varias las razones que pudieron llevarle a este cambio de residencia. La primera, y más genérica, atendería al establecimiento en una comunidad irlandesa, tal como la descrita, fuertemente asentada en la ciudad donde la integración no representaría graves problemas y permitiría un proceso de asimilación más natural. Por otro lado, podrían existir lazos familiares que le llevaran a cohabitar con algún pariente asentado en el puerto bretón. La bibliografía describe la presencia de la familia de origen irlandés Everard en Bretaña (Silke, 1991, pp. 613-4); no obstante, la presencia del apellido en los registros parroquiales de Saint Malo no es particularmente destacada ${ }^{14} \mathrm{y}$, en cualquier caso, al ser un apellido de origen normando con una evolución grafológica similar en Irlanda y en Francia parece complicado discriminar entre los individuos de ambas ramas o ascendencias. Sin embargo, resulta más plausible que los lazos familiares que le acercaran a Saint Malo fueran los de su mujer, Grac(ienn)e Butler. Al contrario que con Everard, el apellido Butler surge recurrentemente en los archivos de la villa bretona durante la primera década de 1700 (Nicolas, 2000), y a pesar de no poderse establecer ninguna conexión directa entre Grace Butler y algún familiar, puede especularse con ello, más teniendo en cuenta que mayoritariamente procedían de Waterford, al igual que ella. Una tercera motivación para el traslado de Raymond desde París hasta Bretaña podría relacionarse con su profesión médica. La obtención de un título de médico para ejercer en París o en otros núcleos de población franceses importantes era dificultosa en términos de tiempo y dinero, y el título obtenido en la Facultad de Champagne impedía a Everard ofrecer sus servicios médicos tanto en París como en Reims. Saint Malo contaba con un importante hospital a comienzos del siglo XVIII y es posible que ello atrajera al recién graduado médico a la villa bretona como lugar para ampliar sus conocimientos y obtener un salario, bien trabajando en el citado hospital o bien como médico libre en una ciudad con numerosos potenciales pacientes de origen irlandés. Incluso pueden encontrarse perfiles académico-profesionales como el de Everard, que podrían haberle servido de modelo a seguir. En 1694, Pierre Archibold -de origen dublinés- ejercía como médico en Saint Malo ${ }^{15}$, quien había obtenido su título -al igual que Everard- en la facultad de medicina de Reims años antes ${ }^{16}$.

La primera referencia del matrimonio Everard-Butler en Saint Malo aparece en 1705, cuando Raymond figura como testigo del enlace entre Felix McCabe y Marie Michelle ${ }^{17}$. En la primavera de 1706, Grace Butler traía al mundo dos hermanas gemelas, Marie Anne y Anne Grace ${ }^{18}$. La segunda moriría pocos días después de su nacimiento y sería enterrada en la cercana parroquia de Saint-Meloir-des-Ondes ${ }^{19}$, a unos $10 \mathrm{~km}$ de Saint Malo. No se dispone de información para explicar por qué Anne Grace Everard fue enterrada en una parroquia que, aunque próxima, no fuera malouine. Podría sugerirse que por aquel entonces la pareja Everard-Butler viviera a medio camino entre ambos enclaves, o tal vez alguien se hiciera cargo de la recién nacida mientras su madre se recuperaba del parto doble ${ }^{20}$. Dos años más tarde, en octubre de 1708, Grace Butler alumbraría una nueva hija, Elisabeth Gratienne ${ }^{21}$. Esta vez el desenlace del nacimiento tendría peores consecuencias aún. Como resultado de lo que parece que fue un parto complicado, la niña moriría a los tres $\operatorname{días}^{22}$ y la madre lo haría nueve días después, siendo enterrada en la catedral de Saint $\mathrm{Malo}^{23}$. Además de las tres niñas se conoce que Raymond tuvo un cuarto hijo, Diego -ó Jacques-, probablemente en Saint Malo entre 1702 y $1706^{24}$.

Durante la estancia de Everard en Saint Malo existían dos hospitales: el Hôtel-Dieu, que llevaba operativo desde el siglo XIII y tuvo una importante ampliación a comienzos del XVII; y el Hôpital Général, recientemente establecido en 1679 en el área de Saint Servan. La documentación relativa a ambos hospitales durante la primera década de 1700 es compleja y de difícil revisión, y entre la información estudiada no aparece el nombre del médico irlandés. Sin embargo, pudo haber ejercido en el hospital en un puesto secundario y esporádico -los propios médicos titulares atendían el hospital en turnos trimestrales- y compaginar esas labores con las visitas rea- 
lizadas como médico libre. Dado que la regularización de la profesión médica en Saint Malo no llegó hasta algún año después, la normativa era más indulgente con el ejercicio libre de tales prácticas y es muy probable que Everard actuara de este modo (Hervot, 1905, pp. 91-133).

La población de Saint-Malo a comienzos del siglo XVIII era de unos 25.000 habitantes (Garnot, 1998, p. 16); por añadido, el tráfico de navíos en su puerto era muy elevado, con las numerosas enfermedades asociadas a las prácticas marítimas de la época, esto es, las propias de las largas travesías oceánicas, así como las asociadas a los encuentros violentos entre embarcaciones militares, y las capturas de corsarios y piratas sobre las vías mercantes. Ello aseguraba, sin duda, la necesidad de los servicios médicos en la villa, más si cabe, en una época en la que los índices de asistencia médica de población eran muy bajos.

Como era habitual durante los s. XVII-XVIII, las comunidades irlandesas establecidas a lo largo del Atlántico se encontraban muy cohesionadas $y$, aunque su integración en el lugar de acogida era efectiva en mayor o menor grado, se practicaban comportamientos con cierto carácter endogámico o de apoyo del colectivo. A través de la información relativa a Everard durante su estancia en Saint Malo este parecía ser el caso. Tal hecho se manifiesta particularmente en el apadrinamiento de sus hijos, que tuvo carácter irlandés casi en exclusiva. Anne Grace fue apadrinada por Pierre Nicolas Geraldine -hijo de irlandeses e importante armador de la villa-, y Helene Cheneau -esposa del irlandés Francis Browne. Marie Anne compartió el padrino de su hermana, mientras que su madrina fue Marie Lombard -hija de irlandés. En el caso de Elisabeth Gratienne el padrino fue Jan Talbot -capitán de navío irlandés, en ocasiones al servicio del armador Richard Butler-y Elizabeth Knowles. Por añadido, el único registro en el que aparece Raymond como testigo o padrino resulta ser el enlace matrimonial de Felix McCabe y Marie Michel, en el que aparecen testigos irlandeses en exclusiva ${ }^{25}$. Es relevante que, más allá de la procedencia irlandesa de los padrinos, en su mayor parte eran personalidades bien establecidas en la sociedad malouine y con cargos o actividades socio-económicas que les otorgaban cierta prominencia en los asuntos de la ciudad. Todo ello induce a pensar que Everard se relacionaba con una clase socio-económica de elevado estrato, en la cual se habría asentado bien por la posición que su familia política -los Butler- podía ostentar o bien por haber conseguido un estatus asociado a su condición de médico (Sée, 1925, pp. 140-2).

\section{BILBAO: MÉDICO MUNICIPAL}

En 1710, Raymond Everard se encontraba ya en Bilbao junto con su hijo Diego ${ }^{26}$. Este cambio de residencia puede apuntarse que fue debido a un conjunto de varias circunstancias y razones. A nivel personal, la pérdida de su mujer debió marcarle profundamente y pudo ser un motivo para cambiar de aires y comenzar una nueva vida. Por añadido a la muerte de su mujer, hay que hacer notar que en un período de dos años había perdido tres hijas, lo cual tuvo que resultarle difícil de asimilar. De este modo, más allá de sus logros y progresos profesionales, los pocos años vividos en Saint Malo representaron una etapa que se saldó de un modo aciago. Este único aspecto pudo haber llevado a Everard a buscar nuevos horizontes en las tierras peninsulares.

A nivel socio-profesional, hubo otros condicionantes que pudieron facilitar esta migración. A comienzos del siglo XVIII, la monarquía española pasó a ser borbónica y toda influencia francesa era vista con buenos ojos. Así, los médicos procedentes del país de Luis XIV -abuelo del rey español- encontraban fácil acomodo en España. Por otro lado, desde la época de Carlos V los irlandeses podían obtener la naturalización española con los mismos derechos que los propios españoles, lo cual proporcionaba la posibilidad de acceder a cargos públicos, y en general, unas mayores alternativas de progreso. Desde el punto de vista profesional, los médicos formados en las grandes universidades europeas -como la de París-podían ofertar unas capacidades que les posicionaran, a los ojos de ciertos clientes, de forma preferente respecto al ejercicio médico español (White, 2008).

En cuanto al por qué de la elección de Bilbao como destino en su nueva etapa cabe pensar en varios motivos. Bilbao se situaba por aquel entonces entre los puertos comerciales más importantes del Atlántico y, por lo tanto, la conexión con el puerto de Saint Malo era común (Zabala, 1983). Esta comunicación permitía la llegada de noticias sobre la próspera comunidad irlandesa asentada en el Señorío de Vizcaya a comienzos del siglo XVIII, e incluso la visita de los propios comerciantes irlandeses residentes en Bilbao que viajaban a las importantes plazas de comercio para ampliar sus negocios. Las redes familiares de los emi- 
grados irlandeses eran extensas, en un sentido geográfico, a lo largo del siglo XVIII, de tal modo que las relaciones que estableciera Everard en Saint Malo pudieron haber condicionado su destino. Por ejemplo, en el puerto bretón mantuvo amistad con Edmundo Shee, oriundo de Dublín, quien acabaría emigrando también a Bilbao, se desconoce si en compañía de Raymond, antes, o después del traslado de este último. Por añadido, el consistorio bilbaíno demostró a lo largo de la primera mitad de siglo un manifiesto interés por la contratación de profesionales de la medicina de probadas capacidades y formados en las corrientes más avanzadas del momento, tal como fue el caso de Juan Cabriada -a quien se intentó captar como médico municipal cuando ejercía en la propia corte española- o el cirujano francés Juan Dargain -cuyas buenas artes se disfrutaban en la corte francesa (Gondra, 2003, p. 39). Es posible que esta inquietud de las instituciones de Bilbao ya se hubiera declarado desde los primeros años del siglo XVIII y, enterado Everard de este empeño, supusiera un estímulo añadido para su traslado.

En 1710 Everard comenzaba una nueva etapa de su vida en una nueva ciudad y con una nueva esposa. El 10 de junio de 1710 contraía matrimonio con María Murphi (sic) en la parroquia del Señor Santiago de Bilbao $^{27}$. Mary Murphy, era otra irlandesa emigrada a Bilbao a finales del siglo XVII. Mary nació en 1682 en el condado de Waterford, donde vivían sus padres Gerard Murphy y Katherine FitzPatrick. Siendo Mary aún de tierna edad su madre falleció, y su padre, viudo y ante la inestable situación socio-política del momento ${ }^{28}$, decidió emigrar a Bilbao con su hija. Aunque Gerard Murphy no parece que llegara a ser un personaje particularmente notorio de la villa bilbaína, sí hay referencias a su participación en el incipiente comercio de la ciudad, operando al menos a lo largo de la cornisa cantábrica, y quizá con otros puertos europeos (Zabala, 2006, p. 340). Así, puede considerarse que María se crio desde muy joven en la sociedad bilbaína; sin embargo, su enlace se mantuvo fiel a las prácticas habituales de la comunidad irlandesa, por la cual la principal vía de integración de los recién llegados se apoyaba en los enlaces con otras irlandesas o hijas de irlandeses residentes en Bilbao. Puesto que a comienzos del siglo XVIII primaban las pautas sociales del Antiguo Régimen y los enlaces entre diferentes clases sociales eran atípicos, se podría pensar que los Murphy habrían alcanzado una cierta posición en la sociedad bilbaína, y que el enlace de Mary con Raymond Everard mantenía esa homoge- neidad de capas sociales. En efecto, se conoce que esta última era pariente cercana del arzobispo de Dublin ${ }^{29}$

El matrimonio de Raymond y Mary perduró hasta la muerte de esta última, 37 años después; y de la pareja nacieron siete hijos: Eduardo Benito (1711), Clara Josepha (1712), María Josepha (1713), Cathalina Francisca (1716), Nicolasa Isabela (1718), Joana Ramona (1721) y María Ángela (1722). De todos ellos, pocos se mantuvieron en Bilbao, salvo su primogénito Eduardo, que tomó los hábitos religiosos y falleció en la misma ciudad ${ }^{30}$.

En 1726 Raymond presentaba su solicitud de avecindamiento y su hidalguía en la villa bilbaína, acreditando para ello tanto su condición de católico -indispensable para residir en los territorios de la monarquía hispánica en igualdad de derechos que los españoles, según decreto real- como su genealogía, origen y nobleza de sus apellidos. Ese mismo año, pues, se le concedía el Sello Mayor para la residencia en tierras vizcaínas, tal como exigían los fueros ${ }^{31}$. Curiosamente, para ejercer como médico municipal era preciso, además del título de doctor, la presentación de su hidalguía, trámite que como se indica, no se concluyó hasta 10 años más tarde de ser contratado por el consistorio bilbaíno.

Mary falleció el 29 de octubre de $1747^{32}$. Y Raymond lo haría siete años más tarde, el 3 de julio de 1754 , siendo sepultado un día después en la catedral de Santiago junto a su esposa ${ }^{33}$. El hecho de que la pareja recibiera sepultura en la parroquia de Santiago -la principal de la villa- apunta de nuevo a un cierto estatus dentro de la sociedad bilbaína, puesto que la mayor parte de los irlandeses residentes en Bilbao eran enterrados en el convento de San Agustín, extramuros de la ciudad.

\section{EL EJERCICO MÉDICO DE EVERARD EN BILBAO}

En 1710, una vez casado y asentado en Bilbao, Everard trató de seguir ejerciendo su profesión de médico en la villa vizcaína. Para cualquier profesional que quisiera trabajar como tal en los territorios de la Corona de Castilla era preciso que dispusiera de la autorización y aprobación de su título por parte del Protomedicato de Castilla. Y así lo realizó el médico irlandés. Un año después de su llegada, en 1711, Everard se desplazó a Madrid con objeto de presentar 
su acreditación académica en Medicina por la Universidad de Reims y someterse a examen ante el Protomedicato. Este fue llevado a cabo por el tribunal conformado por los doctores Don Juan Guerrero, Don Juan Jiménez Cortes y Don Francisco de la Cruz, y fue superado satisfactoriamente. De tal modo, el 8 de abril de 1711 Claude Burlet y Fulgencio Benabent médicos reales y Protomédicos de Castilla- libraron título de doctor a Raymundo Everardo para que ejerciera libremente en la Corona de Castilla ${ }^{34}$.

Superado este trámite administrativo, pocos meses más tarde Everard ejercía ya como médico libre en Bilbao, tal como atestiguan algunas recetas emitidas para el tratamiento de Juan Antonio de Basurto ${ }^{35}$. Es indicativo que al poco tiempo de establecerse en la villa de Bilbao atendiera a personalidades bien posicionadas en la sociedad bilbaína -como la familia Basurto-, lo que hace presumir que o bien estaba avalado por buenas referencias o bien sus buenas artes se hicieran manifiestas rápidamente en la capital vizcaína.

Tras unos años actuando como médico suelto, el 1 de mayo de 1716 Raymond Everard comenzó a trabajar como médico municipal para el ayuntamiento de la villa de Bilbao. El contrato se firmó en 1717, con carácter retroactivo y por una duración de cuatro años. A partir de este momento y hasta su muerte en 1754, Everard continuó firmando contratos de renovación como médico municipal por períodos cada vez más extensos, en 1723, 1724, 1728, 1737, 1747 ${ }^{36}$. Así pues, Raymond Everard ejerció como médico municipal de Bilbao por más de 38 años, entre 1716 y 1754, si bien hay constancia de que durante sus últimos años la edad limitaba sus capacidades y, por tanto, sus obligaciones como representante municipal: "don Raymundo Everardo se halla en avanzada hedad y por lo tanto imposibilitado a la prompta asistencia de los accidentes que pueden acaecer de noche $e^{137}$. A la vista de estos registros puede referirse al médico irlandés como uno de los que más tiempo se ocupó de la población bilbaína, tanto en su cargo como médico oficial como en la totalidad de su carrera.

Los acuerdos recogidos en el contrato de Everard -así como para los demás médicos municipales-con el consistorio bilbaíno contemplaban una serie de obligaciones reguladas en las ordenanzas municipales redactadas ya desde 1515 , y que consideraban los siguientes aspectos:

Atender gratuitamente a los pobres del hospital y de la cárcel. De acuerdo con las escrituras de su contrato, los tres o cuatro titulares se solían distribuir esta actividad por trimestres o cuatrimestres, de tal forma que cada uno atendía en exclusiva a los enfermos del hospital durante tres o cuatro meses y quedaba libre de esta obligación el resto del año.

Residir en el casco urbano y asistir a los vecinos de la Villa en todas las horas del día y de la noche, cuando sea solicitado su servicio, cobrando los estipendios acostumbrados.

No ausentarse de la Villa sin permiso del alcalde, y cuando así lo hiciera, deber de poner un sustituto a su cargo. También en caso de enfermar debía seguir la misma conducta.

Obligación de escribir él mismo las recetas y comprobar su ejecución por parte del boticario, así como su precio.

A partir del año 1661 suele constar la obligación de extender los volantes de ingreso en el hospital de los enfermos, indicando las causas del mismo (Gondra, 2005, p. 49).

De muchos de estos aspectos queda constancia en la documentación de archivo relativa a Everard. Así, las visitas a la cárcel parecían ser comunes. En 1723, Everard, junto con el cirujano municipal Ignacio de Ibarreche, reconoció a un preso inglés, que aquejaba de dolores renales ${ }^{38}$. Entre finales de 1741 y durante los primeros meses de 1742 , fue requerido por el alcaide de la cárcel de Bilbao para la asistencia médica de numerosos presos ingleses, fruto de una captura corsaria ${ }^{39}$.

De igual modo, son varias las recetas que pueden encontrarse firmadas por Raymundo Everardo a lo largo de sus años de ejercicio en Bilbao para los habitantes de la villa: Juan Antonio y Agustín de Basurto, Isabel Pau, Francisco de Lecanda, Antonio de Maruri, etc.

En cuanto a su residencia hay constancia de que la familia Everard residía en una céntrica vivienda ubicada en la confluencia de la calle Correo y el Arenal bilbaíno ${ }^{40}$. Además de la buena ubicación en el casco urbano de la villa -como requerían las ordenanzas para sus doctores-, la residencia debía estar dotada de cierto toque de distinción, puesto que en la misma calle Correo habitaba el señor Corregidor del Señorío de Vizcaya (Kerexeta, 1992, p. 297).

A lo largo del siglo XVIII, la villa bilbaína estuvo atendida por tres o cuatro médicos titulares en función del momento y las circunstancias asociadas (Gondra, 2005, pp. 47-8); que, como se ha indicado, se repartían las asistencias comunitarias de hospital y cárcel, así como las visitas particulares al resto de ciudadanos. En estas fechas, ya no se realizaba una 
distinción en base al salario recibido como médico principal o médico ayudante, sino que todos ellos tres o cuatro según el año-, recibían una cantidad de 300 ducados anuales por igual. Sin embargo, esta cantidad cambió precisamente a la firma del primer contrato de Everard, donde los nuevos firmantes -el propio Everard y Juan Florencio de Miranda- pasaban a cobrar 200 ducados anuales. Esta remuneración discriminatoria respecto de las soldadas del tercer médico Francisco Lloret, quien había firmado su contrato en 1714 por los indicados 300 ducados, incitó a ambos médicos a llevar a cabo una reclamación formal contra el consistorio bilbaíno el mismo año del inicio de su titularidad municipal de $1717^{41}$. La resolución del ayuntamiento fue otorgarles la subida de 100 ducados solicitada; sin embargo, dos meses después del dictamen de la villa una Provisión Real anulaba el auto y ordenaba que tales salarios se atuvieran a la escritura firmada manteniendo la retribución en 200 ducados $^{42}$. De este modo, la cantidad se mantuvo hasta la siguiente renovación de contrato donde Everard recuperó de nuevo los 300 ducados que establecía la villa para sus médicos titulares.

A lo largo de todo el siglo XVIII se produjo en Bilbao una fuerte disputa entre el gremio médico, por la cual los médicos titulares o asalariados por el ayuntamiento reclamaban que no se permitiera el ejercicio médico de otros profesionales que lo hacían de modo libre como médicos sueltos. Esta querella se hizo pública recurrentemente en varios momentos y de formas diversas. El propio Everard, junto con los otros médicos titulares del momento -Irigoiti y Ezquerra-, realizó en 1744 una protesta formal ante el consistorio sobre la práctica ilegítima de otros profesionales que cultivaban sus artes libremente ${ }^{43}$. Años antes, en 1733 , fueron las propias instituciones municipales las que, a través del Corregidor y por orden del Consejo de Castilla, habían solicitado la ratificación de los títulos de médicos, cirujanos, boticarios y sangradores que ejercían en la villa de Bilbao, con el fin de evitar la práctica fuera del control y de la autorización del Real Protomedicato de Castilla ${ }^{44}$. La pugna llegó a su momento más extremo cuando Juan Miranda, médico titular a la vez que Everard en 1716, fue a visitar a un enfermo y al llegar al hogar de este encontró a uno de los médicos sueltos -Manuel Lahaz- atendiendo al convaleciente. La discusión entre ambos en torno a su derecho a tratar al paciente se elevó de tal modo que acabaron sacando sus espadas y comenzaron a batirse en la propia casa de la visita (Gondra, 2005, pp. 119-123).

\section{CONCLUSIONES}

En los albores de las ideas ilustradas y tras un largo período de tinieblas en el desarrollo de la medicina, durante el cual los médicos españoles habían ejercido anclados en el galenismo clásico como consecuencia de la Contrarreforma, surge en España -al igual que en el resto de Europa- a finales del siglo XVII y comienzos del XVIII una nueva corriente en el modo de entender la medicina, que apunta a nuevas formas y nuevos conceptos. Se trata del movimiento novator, que abarcando en sentido estricto una corriente de pensamiento mucho más amplia, se materializa en la medicina de un modo mucho más rupturista. Fruto de estas nuevas ideas, basadas en el empirismo y el racionalismo, comienza una era de debate científico-médico con posturas muy polarizadas entre los profesionales defensores del galenismo tradicional y los novatores seguidores de las doctrinas promulgadas a lo largo del continente por Boerhaave, Stahl o Hoffman. Sin embargo, esta simplificación del enfrentamiento dual propia de las aproximaciones más clásicas (López-Piñero, 1969, 1979) ha sido recientemente enriquecida con análisis más profundos y con perspectivas más poliédricas que revisan los planteamientos de la historiografía (Pardo-Tomas, 2007).

En todo caso, la división ideológica tomó forma en el territorio peninsular instaurando un debate abierto entre los profesionales médicos. A comienzos del siglo XVIII, la coyuntura socio-económica de Valencia propició la aparición de un grupo de intelectuales y científicos que propugnaban las nuevas corrientes europeas y que abanderaron el movimiento seminal de la medicina de los novatores en España, junto con el núcleo surgido en Sevilla. Entre ellos, destacó la figura de Juan de Cabriada. Su presencia en Madrid entre los médicos reformistas de la corte y sus tempranos escritos -principalmente su Carta filosófica, médicochymica-, que defendían las transgresoras corrientes de la iatroquímica y otros principios renovadores, le confirieron notoriedad rápidamente, tanto entre sus seguidores como entre sus detractores. Fue miembro, acogido a posteriori como fundador, de la Regia Sociedad de Medicina y otras Ciencias de Sevilla, fundada por Muñoz, Peralta y otros novatores sevillanos. En 1709 la carrera de Cabriada se aproximó a Bilbao, fruto de una ostentosa oferta realizada desde el consistorio de la villa; sin embargo, este contrato no llegó a ser efectivo pues el propio monarca anuló su validez (López-Piñero, 1994). 
En cualquier caso, el desmesurado interés del ayuntamiento de Bilbao por la contratación de este insigne novator apunta, junto con otros hechos, a unas inquietudes por la incorporación a la asistencia médica de la ciudad de las nuevas prácticas reformistas de la época pre-ilustrada. Otras muestras de la disposición renovadora de Bilbao fueron, por ejemplo, las "anatomías públicas" realizadas por el cirujano Dargain. Asimismo, la reestructuración del Hospital de los Santos Juanes de Achuri respondía a las nuevas ideologías en el concepto de hospital, que tendía hacia una función más asistencial que como asilo, además de llevar asignado personal propio y establecer una reglamentación sobre el funcionamiento del mismo. También otro de los indicadores de esta vocación modernista bilbaína apunta a la traducción que realizó en 1736 el cirujano de la villa Pedro de Arechabala de la obra Observationes medico-practicae, publicada unos años antes en París por el insigne médico LouisJean Le Thieullier, doctor regente de la Facultad de Medicina de la Universidad de París y médico de cámara de Luis $\mathrm{XV}$, quien representaba la vanguardista posición de la medicina francesa del siglo XVIII. En definitiva, Bilbao respondía desde el punto de vista de la medicina a las nuevas ideas y corrientes (pre) ilustradas europeas.

Se desconoce la orientación profesional de Raymond Everard en la encarnizada polémica de la práctica médica a principios del siglo XVIII. No obstante, hay varios factores que parecen apuntar a una tendencia renovadora en la práctica del médico irlandés. En primer lugar y quizá lo más relevante, Everard se formó en las facultades y escuelas médicas de París, que aglutinaban buena parte de las nuevas corrientes de pensamiento europeas en el campo de la medicina, lo que indica que entraría en contacto y, probablemente, asistiría a las lecciones impartidas por los grandes nombres que postulaban los nuevos modos de abordar la anatomía, la fisiología y la química. En este sentido, otros médicos irlandeses formados en
Francia y que ejercieron en España, tales como Sebastian Creagh o Timoteo O'Scanlan, mostraron perfiles profesionales rupturistas y prácticas médicas innovadoras. Por otro lado, el fallido intento del consistorio bilbaíno por contratar a Cabriada a finales de 1709 coincidió con la llegada a Bilbao de Everard en 1710 , de tal modo que las prácticas médicas de este último pudieron haber servido como sustitutivas de los servicios esperados del valenciano. Aunque Raymond Everard no fue contratado por la villa hasta 1716, ejerció la medicina en Bilbao con título del Protomedicato de Castilla desde 1711 y durante su asistencia como médico no asalariado las autoridades bilbaínas pudieron identificarle como una alternativa para suplir los servicios de Cabriada.

En cualquier caso, el estudio de la inserción de Everard en la coyuntura médica de la Monarquía hispánica en el siglo XVIII parece resultar extremadamente ambicioso en el marco del presente trabajo, bien bajo la mirada más clásica de la controversia dual tradición-novator o bien bajo los múltiples enfoques de las aproximaciones revisionistas más recientes en relación a la llamada "revolución científica" y el propio movimiento novator (López Pérez, 2016; Schmitz, 2018), relegando este análisis a futuros estudios sobre la figura de Everard, junto con otros perfiles afines al del doctor irlandés.

Con esta limitación de alcance nacional, se circunscribe el estudio de Everard a un marco mucho más restringido, como el de la villa de Bilbao; y en este sentido, se constata que los médicos irlandeses ocuparon también espacios locales y menos prominentes que los habitualmente resaltados por la historiografía -como pudo ser la corte o las instituciones militares. Sin embargo, incluso a una menor escala, este colectivo de "segunda línea" jugó su papel como uno de los canales de transmisión de conocimiento, enmarcado en las vías migratorias genéricas de la diáspora irlandesa.

\section{NOTAS}

1. Si bien se dispone de un mayor conocimiento de la llustración vasca ligada al entorno guipuzcoano -principalmente alrededor de los caballeritos de Azkoitia y la fundación de la Real Sociedad Bascongada de Amigos del País-, este movimiento renovador también debe su impulso a focos procedentes de las otras dos provincias vascas, que quizá han sido menos relevante por desconocimiento de las mismas. El propio profesor Astigarraga (2003, p. 24) apunta el gran desconocimiento que se tiene en la actualidad de

la actividad cultural de Bilbao durante la primera mitad del siglo XVIII, lo que hace difícil valorar el movimiento y las inquietudes pre-ilustradas de la villa vizcaína.

2. Archivo Histórico Foral de Bizkaia (AHFB): Genealogías de Carlos Macarti, Edmundo Shee, Diego Egan, Miguel Archer, Juan Mariarti y Edmundo Linch.

3. AHFB: Genealogías, Reg. 30, Gen. 494. 
4. AHFB: Genealogías Reg. 28, Gen. 471.

5. Fueron varios los miembros de la familia Everard que militaron en las filas del ejército de Jacobo II, aunque no se ha podido establecer parentesco directo con Raymond: Captain John Everard, Captain Lucas Everard, James Everard, Lieutenant Patrick Everard, etc. (D'Alton, 1855, p. 247).

6. AHFB: Corregimiento, Leg.3637/006.

7. Bibliothèque municipale de Reims (BMR): Raussin Louis Jérome. Catalogus secundum litterarum ordinem digestus omnium eorum qui laurea apollinari coronati fuerunt in Academia Remensi, a natalibus Facultatis medicae, a die scilicet 21 a anni ad diem destructionis Universatum et Facultatum (1794). Mss 1085. Registre des candidats étrangers au titre de Docteur du Petit Ordinaire de 1679 à 1704. Mss 2702.

8. Promedio obtenido a partir de la edad de titulación de 13 médicos irlandeses graduados en Francia durante los siglos XVII-XVIII. Esta edad se corresponde con el promedio de edad para la ordenación de sacerdotes, cuya educación en cierta medida se asemejaba en duración a la de los médicos (Brockliss 1987, pp. 527-572).

9. AHFB: Genealogías Reg. 30, Gen. 494.

10. AHFB: Genealogías, Reg. 41, Gen. 639.

11. Archives Départamentales Yvelines (ADY), Saint-Germainen-Laye, Registre de baptêmes, mariage et sépultures, 9ạ Septembre 1702.

12. AHFB: Bilbao Antigua, Sig. 0396/012/007; AHFB: Genealogías, Reg. 30, Gen. 494. Curiosamente las familias Everard y Butler ya habían emparentado previamente en Irlanda (co. Tipperary y co. Waterford), lo que podría apuntar a un posible matrimonio concertado fundado en las relaciones previas de ambas familias.

13. Archives du Ministère des Affaires Étangères (AMAE): Paris, Ms. 1508, p.329-36: 'État et rolle des irlandais catholiques habituez en Bretagne'.

14. Durante la estancia de Raymond Everard en Saint Malo (aprox. 1703-1708) únicamente se registra en la ciudad una Henriette Helene Eberard, como madrina de un bautismo en 1706 (Archives Communales de Saint-Malo (ACSM), série GG, registre de baptêmes, mariage et sépultures, 4 Août 1706).

15. ACSM, GG, 1 Janvier 1694.

16. BMR, Ms. 1085, 21 maii 1685.

17. ACSM, GG, 8aㅗ Septembre 1705.

18. ACSM, GG, 1a Juin 1706.

19. ACSM, GG, 9a Juin 1706.

20. Aunque la presencia irlandesa no fuera muy notable en la villa de Saint-Meloir-des-Ondes, sí se puede encontrar al- gún apellido irlandés -por ejemplo, Sullivan-, con quien tal vez los Everard tuvieran algún tipo de lazo.

21. ACSM, GG, 16a Octobre 1708.

22. ACSM, GG, 19a Octobre 1708.

23. ACSM, GG, 28a Octobre 1708.

24. Según declaración de Edmundo Shee: "fallecio (...) la referida doña Maria Gracia dejando a su hijo de tierna edad" (AHFB: Bilbao Antigua, Sig. 0396/012/007. AHFB: Genealogías, Reg. 30, Gen. 494).

25. Además de Raymond Everard figuran Thomas Fitzmaurice, Patrik Reilly y Katherine Reilly. (ACSM, GG, 8a Septembre 1705).

26. Único hijo declarado en tal fecha en los archivos vizcaínos, lo que hace pensar que también Maire Anne había fallecido durante su etapa en Saint Malo.

27. Archivo Histórico Eclesiástico de Bizkaia (AHEB): Libro de casados y velados - Señor Santiago de Bilbao, 1690 - 1718.

28. A partir de las referencias de la edad de Mary, nacida en 1682 y siendo de tierna de edad en el momento de la salida de Irlanda, puede estimarse que coincidiera con la época de la Guerra de los Dos Reyes, o la propia capitulación de Limerick de 1691, que desencadenó la masiva salida católica de Irlanda.

29. AHFB: Genealogías, Reg. 30, Gen. 494.

30. AHEB: Libro de difuntos - San Nicolás de Bari de Bilbao, 1693-1773.

31. AHFB: Genealogías, Reg. 30, Gen. 494.

32. AHEB: Libro de difuntos - San Nicolás de Bari, 1693-1773.

33. AHEB: Libro de difuntos - San Nicolás de Bari, 1693-1773.

34. AHFB: Corregimiento, Leg. 3637/006.

35. AHFB: Corregimiento, Leg. 1654/005.

36. AHFB: Bilbao Antigua, Sig. 0177/001/025, Sig. 0082/001/023, Sig. 0082/001/024, Sig. 0082/001/025, Sig. 0463/001/025, Sig. 0466/002/010, Sig. 0469/001/006.

37. AHFB: Bilbao Antigua, Sig. 0020/010/001.

38. AHFB: Corregimiento, Leg. 4045/004.

39. AHFB: Corregimiento, Leg. 0780/024.

40. AHEB: Libro de casados y velados - San Nicolás de Bari, 1700-1753.

41. AHFB: Bilbao Antigua, Sig. 0177/001/031.

42. AHFB: Bilbao Antigua, Sig. 0019/001/034.

43. AHFB: Bilbao Antigua, Sig. 0020/010/001.

44. AHFB: Corregimiento: Leg. 0883/022. 


\section{BIBLIOGRAFÍA}

Amenedo Costa, Mónica (2010), “Timoteo O’Scanlan: vida pública y privada en El Ferrol ilustrado", Garoza: revista de la Sociedad Española de Estudios Literarios de Cultura Popular, 10, pp. 9-22.

Astigarraga, Jesús (2003), Los ilustrados vascos: ideas, instituciones y reformas económicas en España, Barcelona, Crítica.

Basurto Larrañaga, Román (1983), Comercio y burguesía mercantil de Bilbao en la segunda mitad del siglo XVIII, Bilbao, Servicio Editorial Universidad del País Vasco.

Beltrán, Juan Ramón (1939), Epistolario de Miguel Gorman, Buenos Aires, Universidad de Buenos Aires.

Brockliss, Lawrence (2009), “Étudiants de médecine des îles britanniques inscrits en France sous l'Ancien Régime ". En: Ferté, Patrick; Barrera, Caroline, Etudiants de l'exil: Migrations internationales et universités refuges (XVIe-XXe siècle), Toulouse, Presses Univ. du Mirail, pp. 81-104.

Brockliss, Lawrence (2010), "Medicine, Religion and Social Mobility in Eighteenth- and Early Nineteenth-Century Ireland". En: Clark, Fiona; Kelley, James, Ireland and medicine in the seventeenth and eighteenth centuries, Farnham, Ashgate, 2010, pp. 73-108.

Brockliss, Lawrence; Ferté, Patrick (1987), "Irish Clerics in France in the Seventeenth and Eighteenth Centuries: A Statistical Study", Proceedings of the Royal Irish Academy. Section C: Archaeology, Celtic Studies, History, Linguistics, Literatura, 87C, pp. 527-572.

Clarke de Dromantin, Patrick (2005), Les réfugiés jacobites dans la France du XVIIle siècle: l'exode de toute une noblesse "pour cause de religion, Bordeaux, Presses Univ de Bordeaux.

Chambers, Liam (2006), "Rivalry and Reform in the Irish College, Paris, 1676-1775". En: O'Connor, Thomas; Lyons, Mary Anne (eds), Irish Communities in Early Modern Europe, Dublin, Four Courts Press, pp. 103-129.

Chambers, Liam (2008), "Irish fondations and boursiers in early modern Paris, 1682-1793", Irish Economic \& Social History, 35, pp. 1-22.

Chaparro D’Acosta, Lino (1983), "Estudio genealógico-heráldico de la inmigración extranjera en Canarias", Congreso Internacional de las Ciencias Genealógica y Heráldica, Volumen 1, Ediciones Hidalguia, pp. 511-540.

D’Alton, John (1855), Illustrations, Historical and Genealogical: Of King James's Irish Army List (1689). Dublin.

Eiras Roel, Antonio (coord.) (2004), La Inmigración en España: Actas del coloquio, Santiago de Compostela, 6-7 de noviembre de 2003, Santiago de Compostela, Universidade de Santiago de Compostela, Servicio de Publicaciones.

Garnot, Benoît (1998), La population française: aux XVIe, XVIle et XVIIle siècles. Paris, Editions Ophrys.

Gelfand, Toby (2010), “Paris: 'certainly the best Place for learning the practical part of anatomy and surgery'". En: Grell, Ole
Peter; Cunningham, Andrew; Arrizabalaga, Jon (eds.), Centres of medical excellence?: Medical travel and education in Europe, 1500-1789, Farnham, Ashgate, pp. 221-247.

Gondra, Juan (2003), "Un cirujano navarro en Bilbao", Osasun zerbitsuak-Servicio de Sanidad, p. 39.

Gondra, Juan (2005), Los médicos de Bilbao: siglos XV al XIX, Bilbao, Museo Vasco de Historia de la Medicina y de la Ciencia.

Guiard Larrauri, Teófilo (1972), Historia del Consulado y Casa de Contratación de la villa de Bilbao: 1511-1699, Bilbao, La Gran Enciclopedia Vasca.

Hervot, (1905), La médecine et les médecins à Saint-Malo 1500 1820. Rennes, Librairie J. Plihon et L. Hommay.

Kerexeta, Jaime (1992), Fogueraciones de Bizkaia del siglo XVIII, Bilbao, Instituto Labayru.

Lario de Oñate, María del Carmen (2001), La colonia mercantil británica e irlandesa en Cádiz a finales del siglo XVIII, Cádiz, Universidad de Cádiz, Servicio de Publicaciones.

Le Noac'h, Alain ; Ó Cíosáin, Éamonn (2006), Immigrés irlandais au XVIle siècle en Bretagne: Du Centre-Bretagne à l'embouchure du Blavet, Tome 1, Vannes, Institut culturel de Bretagne.

López Pérez, Miguel (2016), "Los hijos de Paracelso", Studia Hermetica Journal, 6 (2), pp. 69-105.

López Piñero, José María (1969), La introducción de la ciencia moderna en España, Barcelona, Ariel.

López Piñero, José María (1979), Ciencia y técnica en la sociedad española de los siglos XVI y XVII, Barcelona, Labor.

López Piñero, José María (1994), Joan de Cabriada i la introducció de la ciència moderna a Espanya, Valencia, Generalitat Valenciana.

Lyons, Mary Ann (2000), "The emergence of an Irish community in Saint-Malo, 1550-1710". En: O'Connor, Thomas (ed.), The Irish in Europe, 1580-1815, Dublin, Four Courts Press, pp. 107-26.

Nicolas, Guy, (2000), "L'immigration irlandaise à Saint-Malo du XVle au XVIIIe siècle", Annales de la Société d 'Histoire et $d$ 'Archéologie de I 'arrondissement de Saint-Malo, 2000, pp. 211-272.

Ó Ciosáin, Eamonn (2001), “A hundred years of Irish migration to France, 1590- 1688". En: O'Connor, Thomas (ed.), The Irish in Europe, 1580-1815, Dublin, Four Court Press, pp. 93-106.

Ó Ciosáin, Eamonn (2006), "Regrouping in exile: Irish communities in Western France in the seventeenth century". En: Ó hAnnracháin, Tadhg; Armstrong, Robert (eds.), Community in Early Modern Ireland, Dublin, Four Courts Press, pp 133-151.

O'Connor, Thomas (2004), "Lynch, James (1626-1713)”, Oxford Dictionary of National Biography, Oxford, Oxford University Press. 
O'Connor, Thomas (ed.) (2001), The Irish in Europe, 1580-1815, Dublin, Four Courts Press.

O'Connor, Thomas; Lyons, Mary Ann (eds.) (2006), Irish Communities in Early-Modern Europe, Dublin, Four Court Press.

Pardo-Tomás, José; Martínez-Vidal, Àlvar (2007), “Medicine and the Spanish Novator movement: ancients vs. moderns, and beyond". En: Navarro Brotóns, Víctor; Eamon, William (eds.), Más allá de la Leyenda Negra. España y la Revolución cientifica / Beyond the Black Legend: Spain and the Scientific Revolution (Valencia, Universitat de València - CSIC, 2007), pp. 323-344.

Paris, Louis (1838), La Chronique de Champagne, Vol. 4, Reims et Paris, Techener.

Recio Morales, Óscar; García García, Bernardo José; de Bunes Ibarra, Miguel Angel; García Hernán, Enrique (2002), (eds.), Irlanda y la Monarquía Hispánica: Kinsale 1601-2001. Guerra, política, exilio y religión, Madrid, Universidad de Alcalá, Servicio de Publicaciones: Consejo Superior de Investigaciones Científicas, CSIC

Ridder-Symoens, Hilde (2010), "The mobility of medical students from the fifteenth to the eighteenth centuries: the institutional context". En: Grell, Ole Peter; Cunningham, Andrew; Arrizabalaga, Jon (eds.), Centres of medical exceIlence?: Medical travel and education in Europe, 1500-1789, Farnham, Ashgate, pp. 47-89.

Sée, Henri (1925), La France économique et sociale au XVIIle siècle. Paris, Librairie Armand Colin.

Silke, John J. (1991), "The Irish Abroad 1534-1691". En: Moody, Theodore W.; Martin, Francis X.; Byrne, Francis J., Early Modern Ireland: 1534-1691, Vol. 3, Oxford, Oxford University Press, pp. 587-634.
Schmitz, Carolin (2018), Los enfermos en la España barroca y el pluralismo médico. Espacios, estrategias y actitudes, Madrid, CSIC

Téllez Alarcia, Diego (2002), “'L'exil jacobite irlandais et l'Ouest de la France (1691-1716)". En: Denéchère, Yves ; Marais, Jean-Luc (dirs.), Les étrangers dans l'Ouest de la France (XVIIle-XXe siècle). Annales de Bretagne et des Pays de I'Ouest, 109, pp. 25-40.

Tena, Antonio Lorenzo (2008), "Una colonia irlandesa en la isla de La Palma durante el siglo XVIII", Boletín Millares Carlo, 27. pp. 83-100.

Villar García, María Begoña (coord.) (2000), La emigración irlandesa en el siglo XVIII, Málaga, Universidad de Málaga.

Walsh, Micheline Kerney (1989), "Two 18th Century Medical Doctors in Spain, Felix and Alexander Maguire", Clogher Record, 13(2), pp. 70-83.

White, Michael (2008), "The role of Irish doctors in eighteenthcentury Spanish medicine". En: Downey, Declan M.; Crespo MacLennan, Julio (eds.), Spanish-Irish Relations through the ages, Dublin, Four Courts Press.

Worthington, David (ed.) (2010), British and Irish Emigrants and Exiles in Europe, 1603-1688, Leiden, Brill.

Zabala, Aingeru (1983), El comercio y tráfico marítimo del norte de España en el siglo XVIII, Donostia, Haranburu.

Zabala, Aingeru (1994), Mundo urbano y actividad mercantil, Bilbao 1700-1810, Bilbao, Bilbao Bizkaia Kutxa.

Zabala, Aingeru (2006), "La Guerra de Sucesión en el mar Cantábrico", Itsas Memoria. Revista de Estudios Marítimos del País Vasco, 5, pp. 325-356. 